\title{
Effect of polyamines on parental and hybrid strains of Bombyx mori
}

\author{
Aparna Yerra, Anitha Mamillapalli* \\ Department of Biotechnology, GITAM Institute of Science, GITAM University, Visakhapatnam, Andhra Pradesh, India.
}

\section{ARTICLE INFO}

\section{Article history:}

Received on: 22/08/2016

Revised on: 19/09/2016

Accepted on: 30/09/2016

Available online: 05/11/2016

Key words:

Silkworm, Spermidine,

Spermine, Bombyx mori.

\begin{abstract}
The silk produced by Bombyx mori, mulberry silk, is of very high economic importance. Many hybrid strains of Bombyx mori were developed to improve silk production and to withstand different environmental conditions. Polyamines are low molecular weight polycations present in all living cells. These are very crucial for the growth and survival of organisms. Previous results from our lab showed positive effect of spermidine treatment on CSR $2 \times$ CSR 4 hybrid strain. The present study was taken up to know the effect of spermidine and spermine on different parental and hybrid strains of silkworm. Treatment of these molecules increased body weight, gland weight and cocoon weights. Results showed that both spermidine and spermine enhanced silk production. Our study shows a method for enhancement of silk production by parental strains.
\end{abstract}

\section{INTRODUCTION}

Silkworm breeds or hybrids play a very important role for the development of sericulture industry. Bulk of the silk is produced by Polyvoltine $\times$ Bivoltine cross in India. Bivoltine hybrids were successful to some climatic conditions. Many techniques were developed to produce the silkworm strains to withstand the environmental conditions. Cross-breeding strains, Multivoltine $\times$ Multivoltine $(\mathrm{PM} \times \mathrm{C}$ Nichi, $\mathrm{PM} \times \mathrm{C} 110)$ were developed mainly for rainy seasons; Multivoltine $\times$ Bivoltine $(\mathrm{PM} \times \mathrm{CSR} 2, \mathrm{MH} 1 \times \mathrm{CSR} 2)$ for average climatic conditions and Bivoltine $\times$ Bivoltine $(\mathrm{CSR} 2 \times$ CSR4) for all climatic conditions. Silk produced by bivoltine silkworm is of very high quality. These also produce more amount of silk. These productive strains have been developed by Central Sericulture Research and Training Institute (CSRTI), Mysore. The five strains selected for the present study are the popular strains of South India reared for their superior qualities. Pure Mysore (PM) strain is suitable for all conditions. Their cocoon weight ranges from $0.8 \mathrm{~g}$ to $1 \mathrm{~g}$ and filament length ranges from $325 \mathrm{M}$ to $375 \mathrm{M}$. CSR2 strain is reared from August to February. Its cocoon weight ranges from

\footnotetext{
* Corresponding Author

Dr. Anitha Mamillapalli, Associate Professor, Department of Biotechnology, GITAM Institute of Science, GITAM University Visakhapatnam-530 045, Andhra Pradesh, India.

Email: anitha.mamillapalli @ gmail.com,

Tel: +91891 284046, Fax Number: + 91891790032
}

$1 \mathrm{~g}$ to $1.8 \mathrm{~g}$ and filament length from $1000 \mathrm{M}-1100 \mathrm{M}$. CSR4 strain is reared from August to February. Its cocoon weight ranges from $1.50 \mathrm{~g}$ to $1.075 \mathrm{~g}$ and filament length ranges from $950 \mathrm{M}$ to $1000 \mathrm{M}$. The hybrid, PM $\times$ CSR 2 is reared in all seasons. Its cocoon weight is approximately $1.0 \mathrm{~g}$ and filament length ranges from $758 \mathrm{M}$ to $760 \mathrm{M}$. The well known hybrid, CSR $2 \times$ CSR 4 is widely used strain in South India. Rearing of these worms is suitable from September to February. Its cocoon weight ranges from 1.6 to $1.8 \mathrm{~g}$ and approximate filament length is around 1000M [1, 2]. Polyamines (PA) were shown to be important regulators of cell growth and differentiation were shown to modulate gene expression in a variety of organisms [3, 4, 5 and 6]. PAs were interact with nucleic acids directly [6]. They were shown to play role in regulating the structure of RNA and in translation [7]. Under physiological conditions spermine $(\mathrm{Spm})$ and spermidine $(\mathrm{Spd})$ are better than putrescine in promotion of growth [8]. Previously many works have reported improvement in economic parameters by supplementation with Vitamins [9], Riboflavin and Ascorbic acid $[10,11]$. Recently, genetic approaches were also made to improve silk production by developing transgenic silkworms [12]. Previous results from our lab showed enhancement in silk production on feeding $5^{\text {th }}$ instar silkworms, CSR $2 \times$ CSR 4 strain with Spd. The present investigation was undertaken to evaluate the effect of polyamine treatment on parental and hybrid strains. PM, CSR 2, $\mathrm{CSR} 4, \mathrm{PM} \times \mathrm{CSR} 2$ and CSR2 $\times$ CSR4 were selected. Results showed that the PA fed larvae showed better growth in both parental and hybrid strains. Economic parameters like silk gland weight, cocoon weight and filament length improved in both parental and hybrid strains. 


\section{METHOD AND MATERIALS}

\subsection{Standard Polyamines}

Spermidine free base (RM 5438), Spermine (RM 7506) were purchased from Hi media chemicals.

\subsection{Collection of larvae}

Disease free laying (dfls) of CSR2, CSR4, PM, CSR $2 \times$ CSR 4 and PM $\times$ CSR2 were brought from Andhra Pradesh State Sericulture Research and Development Institute (APSSRDI), Hindupur, Andhra Pradesh, India. The eggs were incubated for hatching and hatched larvae were grown into adult larvae at Government Sericulture farm at Srikakulam. After third moult, the larvae were acclimatized to laboratory conditions by rearing them in plastic trays by providing sufficient ventilation, spraying disinfection and reared at RH $70 \pm 10$ and temperature $28 \pm 2{ }^{\circ} \mathrm{C}$. The larvae were divided into 5 groups in all breeds; one group is set as control and the other four groups are set as treated groups in triplicates. Minimum 30 worms were kept per group. $50 \mu \mathrm{M}$ and $100 \mu \mathrm{M}$ concentrations of each drug were selected. Fresh mulberry leaves were sprayed with PA of different concentration by swab method and fed to the larvae three times per day. Control worms were fed with normal leaf. During fourth moult the larvae were placed on mountage and left undisturbed to form cocoons and on day 13 cocoons were harvested and subjected for estimating cocoon parameters.

\subsection{Estimation of body weights}

Body weights were recorded every alternate day $(1,3,5$ and 7) for 30 larvae from each group by using digital weighing balance. Day 1 weights are taken as initial weights before the drug treatment.

\subsection{Estimation of gland weights}

On day 7 , end of the $5^{\text {th }}$ instar larval stage, worms were scarified for gland weights. Worms were dissected and total silk gland was isolated and weighed. Minimum 3 larvae were scarified per group. Both control and PA treated group larvae silk gland weights were recorded.

\subsection{Estimation of cocoon parameters}

Larvae were allowed to spin and left undisturbed. On day 13 cocoons were harvested and subjected for cocoon weight analysis.

\subsection{Degumming process and silk reeling}

Cocoons of both control and treated groups of different concentration were used for reeling purpose. The cocoons were boiled in hot water for more than 10 minutes to remove the raw silk and boiled in hot water till single fiber is obtained. Single filament from each cocoon was reeled on hand by using epprouvettor of circumference $1.125 \mathrm{~m} /$ rotation with same reeling speed. The number of rotations was multiplied to the circumference to obtain the total filament length.

\section{RESULTS}

\subsection{Effect of PA on body weights}

PA feeding to the larvae showed an increase in the body weights in both parental and hybrid strains (Table 1). Spd $50 \mu \mathrm{M}$, Spd $100 \mu \mathrm{M}$, Spm $50 \mu \mathrm{M}$ and Spm $100 \mu \mathrm{M}$ showed significant increase in body weights of CSR2, PM $\times$ CSR2, CSR 4 and CSR2 $\times$ CSR 4 .

Of all the strains tested for PA feeding, maximum increase in body weights was observed with PM $\times$ CSR2 strain. On the other hand, PM strain did not show any effect on body weights upon PA feeding.

\subsection{Effect of PA on gland weight}

Silk glands were taken for weight measurement from both control and PA fed larvae on day 7 of $5^{\text {th }}$ instar larval stage. PA effect on gland weight was checked for all the strains (Fig 1A). The PM strain showed no effect on silk gland weight upon treatment with polyamines. CSR2 strain showed positive effect on gland weight in all treatments. Significant increase was observed with Spm $100 \mu \mathrm{M}$ treatment. PM $\times$ CSR2 strain showed positive effect at higher concentrations of PAs. CSR4 showed no positive effect with PA treatment. CSR $2 \times$ CSR 4 stain showed positive effect with Spd $50 \mu \mathrm{M}$ and Spm $100 \mu \mathrm{M}$ concentrations. Thus from the results it can be found that the response to PA was different with different strains. Both parental and hybrid strains responded to the treatment.

\subsection{Effect on cocoon parameters}

Control and PA fed larvae were allowed to form cocoons and cocoon weights were analysed on day 13 of the pupal stage (Fig 1B). Parental strain, CSR2, showed better response in cocoon weight with Spd $50 \mu \mathrm{M}$, Spd $100 \mu \mathrm{M}$ and Spm $100 \mu \mathrm{M}$ treatments. The images of cocoons of all strains at different treatments were given in Fig 2.

\subsection{PA treatment on filament length}

The total amount of silk reeled from single cocoon of the strains at different concentrations were analysed (Fig 1C). Spd 50 $\mu \mathrm{M}$, Spd $100 \mu \mathrm{M}$, Spm $50 \mu \mathrm{M}$ and Spm $100 \mu \mathrm{M}$ showed significant increase in filament length in CSR 2 and CSR $2 \times$ CSR 4 strains. CSR4 strain showed positive repose in for filament length with Spd $50 \mu \mathrm{M}$ treatment.

In the present study we found that parental and their hybrids strains were influenced by the PA treatment. PA feeding showed positive effect on body weights, gland weights, cocoon weights and filament length. This result shows correlation to administration of folic acid $[13,14)$ and thiamine on different silkworm races [15]. Both Spd and Spm showed similar effect on silkworm for both growth and economic parameters. 
Table 1: Effect of Spd and Spm on body weights of different B. mori strains.

\begin{tabular}{|c|c|c|c|c|c|c|c|}
\hline \multicolumn{8}{|c|}{ Body weights (gm) } \\
\hline Drugs & Concentrations & Strains & Day-1 & Day-3 & Day-5 & Day-7 & $\begin{array}{l}\text { Percentage increase } \\
\text { in body weight }\end{array}$ \\
\hline \multirow{5}{*}{ Control } & \multirow{5}{*}{---} & PM & $0.56 \pm 0.001$ & $1.41 \pm 0.04$ & $1.88 \pm 0.049$ & $2 \pm 0.052$ & 72 \\
\hline & & CSR2 & $0.78 \pm 0.02$ & $2.6 \pm 0.109$ & $3.04 \pm 0.133$ & $3.57 \pm 0.067$ & 78.15 \\
\hline & & PM* CSR2 & $0.67 \pm 0.001$ & $2.5 \pm 0.041$ & $2.91 \pm 0.052$ & $3.51 \pm 0.062$ & 80.91 \\
\hline & & CSR4 & $0.97 \pm 0.002$ & $2.07 \pm 0.053$ & $2.69 \pm 0.122$ & $3.28 \pm 0.140$ & 70.42 \\
\hline & & CSR2* CSR4 & $0.95 \pm 0.001$ & $3.11 \pm 0.041$ & $3.50 \pm 0.025$ & $4.26 \pm 0.051$ & 77.69 \\
\hline \multirow{10}{*}{ Spd } & \multirow{5}{*}{$50 \mu \mathrm{M}$} & PM & $0.42 \pm 0.002$ & $1.42 \pm 0.141$ & $1.9 \pm 0.141$ & $2.01 \pm 0.083$ & 79.1 \\
\hline & & CSR2 & $0.8 \pm 0.01$ & $3.24 \pm 0.049^{*}$ & $3.68 \pm 0.056^{*}$ & $4.29 \pm 0.060$ & 81.35 \\
\hline & & PM* CSR2 & $0.67 \pm 0.02$ & $2.81 \pm 0.034^{*}$ & $3.32 \pm 0.052^{*}$ & $3.89 \pm 0.127^{*}$ & 82.77 \\
\hline & & CSR4 & $0.92 \pm 0.004$ & $2.94 \pm 0.073^{*}$ & $3.2 \pm 0.10^{*}$ & $3.54 \pm 0.161$ & 74.011 \\
\hline & & CSR2* CSR4 & $0.92 \pm 0.001$ & $3.52 \pm 0.117^{*}$ & $4 \pm 0.08^{*}$ & $4.60 \pm 0.096^{*}$ & 80 \\
\hline & \multirow{5}{*}{$100 \mu \mathrm{M}$} & PM & $0.53 \pm 0.01$ & $1.59 \pm 0.288$ & $1.8 \pm 0.075$ & $2.12 \pm 0.136$ & 75 \\
\hline & & CSR2 & $0.78 \pm 0.02$ & $3.19 \pm 0.049^{*}$ & $3.74 \pm 0.11^{*}$ & $4.26 \pm 0.051$ & 81.69 \\
\hline & & PM* CSR2 & $0.64 \pm 0.01$ & $2.81 \pm 0.034^{*}$ & $3.28 \pm 0.063^{*}$ & $3.89 \pm 0.051^{*}$ & 83.54 \\
\hline & & CSR4 & $1 \pm 0.03$ & $2.65 \pm 0.075^{*}$ & $3.04 \pm 0.11^{*}$ & $3.56 \pm 0.136$ & 71.94 \\
\hline & & CSR2* CSR4 & $0.93 \pm 0.001$ & $3.54 \pm 0.136^{*}$ & $4.02 \pm 0.06$ & $4.59 \pm 0.139^{*}$ & 79.73 \\
\hline \multirow{10}{*}{ Spm } & \multirow{5}{*}{$50 \mu \mathrm{M}$} & $\mathbf{P M}$ & $0.5 \pm 0.010$ & $1.11 \pm 0.10$ & $1.37 \pm 0.04^{*}$ & $1.69 \pm 0.15$ & 70.41 \\
\hline & & CSR2 & $0.69 \pm 0.02$ & $2.2 \pm 0.067^{*}$ & $3.31 \pm 0.118$ & $3.61 \pm 0.111$ & 80.88 \\
\hline & & PM* CSR2 & $0.59 \pm 0.001$ & $1.82 \pm 0.27$ & $3.19 \pm 0.09^{*}$ & $3.47 \pm 0.053$ & 82.99 \\
\hline & & CSR4 & $1 \pm 0.002$ & $2.55 \pm 0.07^{*}$ & $3 \pm 0.23$ & $3.13 \pm 0.11$ & 68.05 \\
\hline & & CSR2* CSR4 & $0.85 \pm 0.004$ & $2.44 \pm 0.378^{*}$ & $3.28 \pm 0.082$ & $4.02 \pm 0.185^{*}$ & 78.75 \\
\hline & \multirow{5}{*}{$100 \mu \mathrm{M}$} & $\mathbf{P M}$ & $0.43 \pm 0.001$ & $1.25 \pm 0.042$ & $1.98 \pm 0.182$ & $1.88 \pm 0.100$ & 77.12 \\
\hline & & CSR2 & $0.77 \pm 0.001$ & $3.37 \pm 0.053^{*}$ & $3.61 \pm 0.037^{*}$ & $4.32 \pm 0.029$ & 82.17 \\
\hline & & PM* CSR2 & $0.63 \pm 0.002$ & $2.71 \pm 0.102$ & $3.23 \pm 0.071^{*}$ & $3.84 \pm 0.035^{*}$ & 83.59 \\
\hline & & CSR4 & $0.95 \pm 0.003$ & $2.56 \pm 0.10^{*}$ & $2.80 \pm 0.17$ & $3.48 \pm 0.129$ & 72.7 \\
\hline & & CSR2* CSR4 & $0.94 \pm 0.001$ & $3.76 \pm 0.80$ & $4.42 \pm 0.03$ & $4.95 \pm 0.101^{*}$ & 81.01 \\
\hline
\end{tabular}

Average larval body weights $(\mathrm{n}=20)$ of parental and hybrid strains treated with different concentrations of Spd and Spm. ' \pm ' indicates the standard error values.

'*' indicates the significantly different with $(p<0.05)$.

\section{Fig 1}

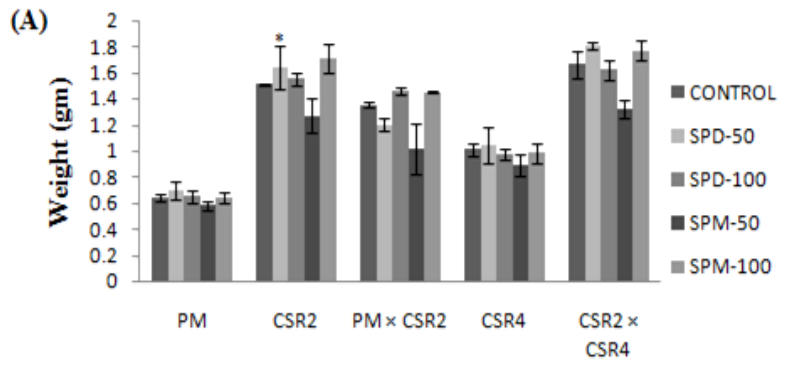

Concentration
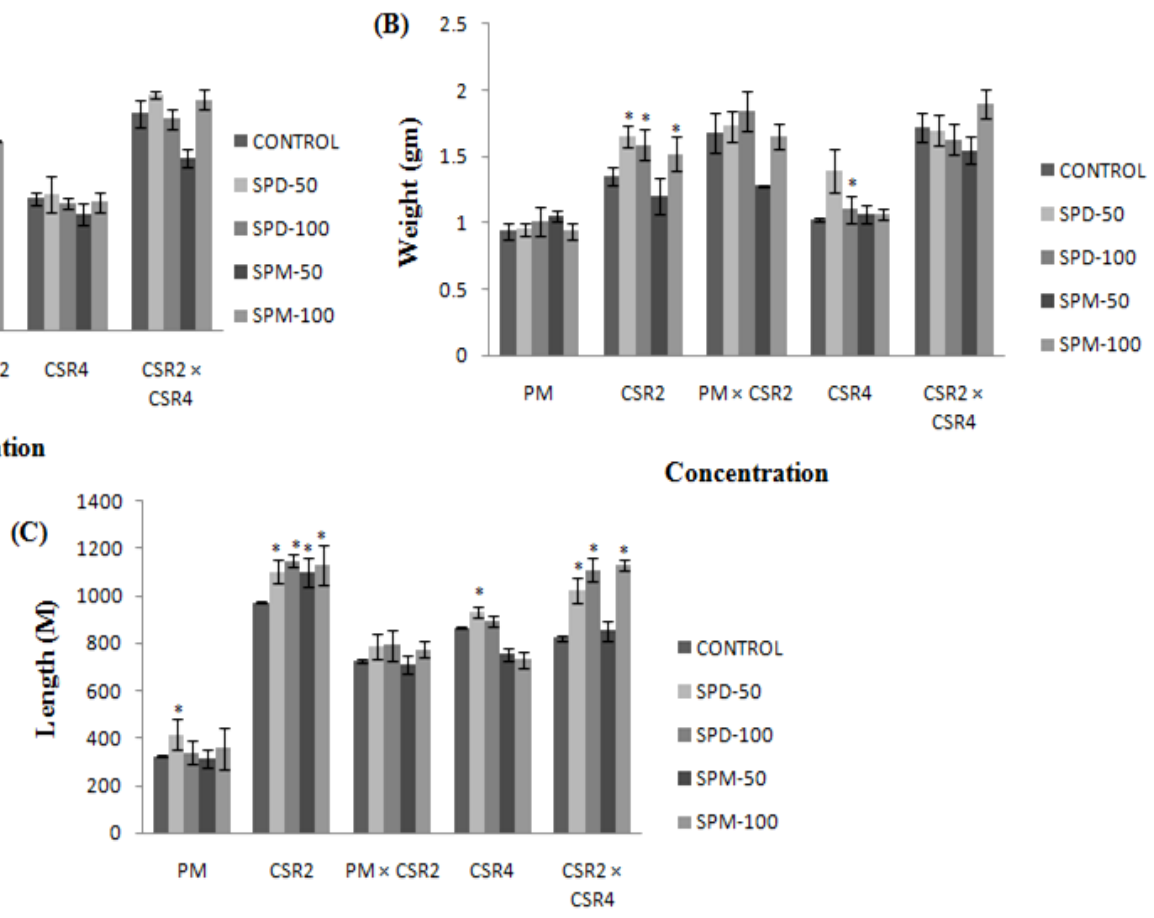

Concentration

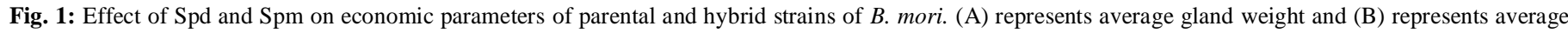



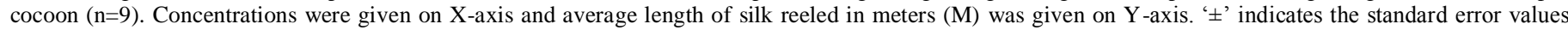
and bars labelled with '*' are significantly different $(p<0.05)$ 

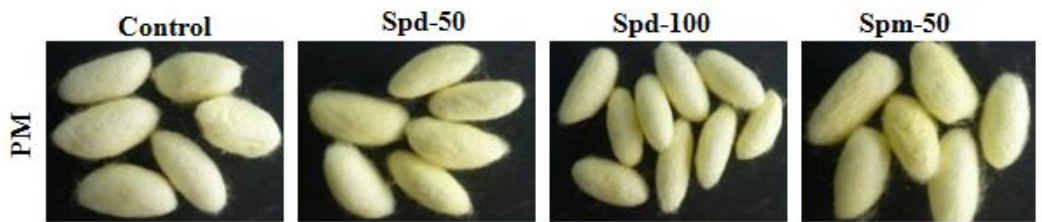

Spm-100
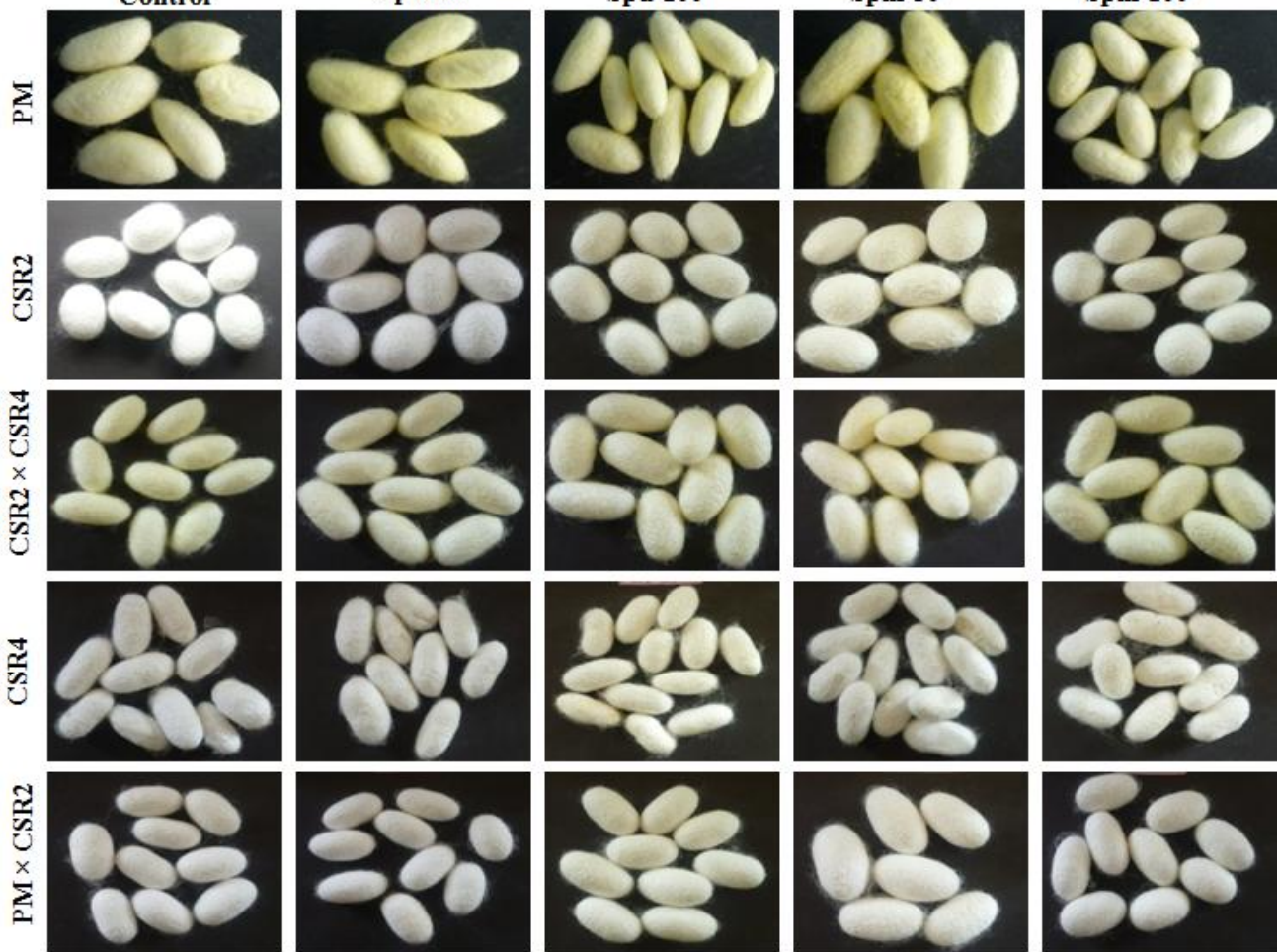

parental and hybrid strains of $B$. mori.

\section{CONCLUSION}

Present study concluded that PA treatments every day to silkworm in their $5^{\text {th }}$ instar stage can enhance the silk production both in parental and hybrid strains.

\section{ACKNOWLEDGEMENTS}

The authors wish to thanks Dr. Ibrahim Basha, ScientistB (FAC) APSSRDI, for supporting and providing different silkworm breeds. The author wish to thanks Mr. K.Satya Rao (Asst. Director) of Andhra Pradesh State Government Sericulture Department, Srikakulam for help in rearing silkworm and in silk reeling.

Financial support and sponsorship: This work was supported by Department of Biotechnology (DBT, Govt. of India, Grant Number: BT/PR15146/GBD/27/337/2011) as DBT-RGYI grant and University Grants Commission (UGC) as UGC - MRP grant (Grant Number: MRP-MAJOR-AGRI-2013-13665) to Anitha Mamillapalli.

Conflict of Interests: There are no conflicts of interest.

\section{REFERENCES}

1. Dandin S.EL, Asavaraja HK, Suresh Kumar N. Sikworm breeds and hybrids at galore. Central Sericultural Research and Training Institute,Central Silk Board, Ministry of Textiles, Govt.of India, Srirampura, Mysore; 2005.
2. Bindroo BB, Naseems Begui A, Mal Reddy N, Moorthy SM. Pedigree of Bivoltine $\left[\mathrm{V}_{2}\right]$ Silkworm breeds (Bombyx mori L.) development at CSRTI; 2014.

3. Tabor H, Tabor CW. Polyamines. Ann. Rev. Biochem. 1984; 53: 749 -790 .

4. Pegg AE. Polyamine metabolism and its importance in neoplastic growth and a target for chemotherapy. Cancer Res. 1988; 48:759774.

5. Ha HC, Woster PM, Yager JD, Casero RA Jr. Influence of drug binding on DNA flexibility: a normal mode analysis. Proc. Natl. Acad. Sci. 1997; 94: 11557 - 11562.

6. Cohen SS. Molecular effects on internal cellular polymers: transfer RNA and DNA. A Guide to the Polyamines. Oxford Univ. Press, New York: 1998; $512-543$.

7. McMurry LM, Algranati ID.Effect of polyamines on translation fidelity in vivo. Eur. J. Biochem. 1986; 155: 383-390.

8. Rouzina I, Bloomfield VA. DNA bending by small, mobile multivalent cations. Biophys. J. 1998; 74: 3152-3164.

9. Das S, Medda A. Effect of cyanocobalamine on protein and nucleic acid contents of ovary of silkworm, Bombyx mori L. during larval, pupal and adult stages of development. Insect Sci. Appl. 1988; 9: 641 646.

10. Ito T, Niminura M. Nutrition of silkworm Bombyx mori. Its specific requirement and its nutrition in relation the mineral nutrition of its host plant mulberry Morus indica L. Indian J. Exptl. Biol. 1966a; 4: 31-36.

11. Ito $\mathrm{T}$, Niminura $\mathrm{M}$. Nutrition of silkworm Bombyx mori. XII Nutritive effects of minerals. Bul.Sericult. Expt Sta. 1966b; 20: 373.

12. Nagaraju J. SPECIAL SECTION: RECENT ADVANCES IN SILKWORM BIOLOGY, Application of genetic principles for improving silk production. CURRENT SCIENCE. 2002; 83(4).

13. Nirwani RB, Kaliwal BB. Effect of ferrous and magnesium Sulphate supplementation on some metabolic substances of Bivoltine Silkworm, Bombyx mori L. Korean J. Seric. Sci. 1996a; 38: 118-123. 
14. Rai MM, Rathod MK, Khurad AM. Improvement in economic characters of silkworm Bombyx mori L. by Folic acid administration. Entomon. 2002; 27: 99-104

15. Nirwani RB, Kaliwal BB. Increase of silk production and quantitative changes of Carbohydrate and protein in the fat body and haemolymph after feeding potassium Sulphate to bivoltine Bombyx mori L. Sericologia. 1996b; 36: 523-530.

How to cite this article:

Yerra A, Mamillapalli A. Effect of polyamines on parental and hybrid strains of Bombyx mori. J App Biol Biotech. 2016; 4 (06): 027-031. DOI: 10.7324/JABB.2016.40605 